\title{
\#SheForShe: Increasing Nominations Significantly Increased Institutional Awards for Deserving Academic Women
}

J Gen Intern Med 36(9):2865-6 DOI: $10.1007 / \mathrm{s} 11606-020-06446-1$

(c) Society of General Internal Medicine 2021

Background. The majority of academic award recipients across medical specialties have been men. ${ }^{1-4}$ Over a decade ago, women received $28 \%, 29 \%$, and $10 \%$ of research, teaching, and clinical awards respectively at one institution. ${ }^{5}$ Since award recognition can be important for promotion, funding, and status at institutional, regional, and national levels, we deployed and evaluated a pilot award nomination intervention aiming to increase the proportion of deserving female award recipients by increasing the number of nominations of deserving women faculty at the University of Chicago.

Methods. This was a pre/post evaluation of a pilot program within our institution's Department of Medicine (DOM; current faculty; $n=319$, women $=139 / 319 ; 43 \%$ ) and Biological Sciences Division (BSD; current faculty; $n=981$, women $=$ 394/981; 40\%). We developed a sub-committee of 3-4 members within our DOM Women's Committee (DOM-WC) through a volunteer process. Next, we obtained historical lists of recipients of local awards to examine gender distribution and identify previous awardees. We then piloted our nomination intervention: (1) identifying eligible female award nominees using a multi-modal approach including suggestions from the DOM-WC members (representing DOM sections), systematically reviewing section faculty lists, and DOM section leaders; (2) notifying worthy nominees of our intent to facilitate their nomination; and (3) shepherding the nominations through to submission, including composing nomination letters and/or seeking qualified letter writers and ensuring that materials (e.g., letters of support, curriculum vitae) were submitted on time. We nominated one woman for each available local award per year. Each nomination typically took less than $3 \mathrm{~h}$ for nominator identification, letter writing, and submission; approximately one-third to one-half of letters were written/edited by our committee. We determined the average

Received May 13, 2020

Accepted December 13, 2020

Published online January 26, 2021 percentage of women award recipients across all available preintervention and post-intervention years and determined whether there was a significant change in the gender distribution using chi-square tests. Award types included clinical, educational, research, and other (diversity, leadership, community service). To account for national trends that may have led to decreasing gender disparities, we conducted a sensitivity analysis limiting our pre-intervention period to the same number of years as the post-intervention period for both DOM (2 years) and BSD (3 years).

Results. Historical awardee lists were available from 2006 to 2016 (DOM) and 2011 to 2017 (BSD). Pre-intervention, 36\% (range $=25-50 \% ; n=79 / 217)$ and $27 \%$ (range $=18-57 \% ; n=$ 28/102) of awardees were women in the DOM and BSD, respectively (Table 1). The intervention was implemented in 2018 (DOM) and 2017 (BSD). The percent of women awardees significantly increased to $56 \%$ (range $=48-65 \% ; n$ $=23 / 41 ; p=0.02)$ and $59 \%($ range $=55-65 \% ; n=33 / 56 ; p=$ 0.00001 ), in the DOM and BSD post-intervention, respectively. The sensitivity analysis found that results remained significant when restricting to similar pre- and post-number of years (DOM pre-intervention: 35\%, range 33-37\%, $n=14 / 40, p=$ 0.06 ) (BSD pre-intervention: $34 \%$, range $=18-43 \%, n=13 /$ $38, p=0.02$ ). Increases in the proportion of female awardees were seen across all award types (educational, clinical, research, and other (Table 2)).

Conclusions. We found that a simple low-resource intervention significantly increased the proportion of women receiving local awards at our institution. Because we did not implement interventions regarding the decision process, it is possible that preintervention, qualified women were being overlooked. It is important to note that implicit bias could still impede deserving women from receiving recognition for awards, for instance among trainee evaluations of faculty. ${ }^{6}$ Future work should establish whether interventions can reduce these additional biases. This study had limitations. For instance, our institutional initiative was quite simple; a more complex initiative to increase nominations for regional and national awards may be more difficult but have a greater impact on promotion. Furthermore, our study was only done at one institution limiting generalizability. Evaluating this simple institutional intervention across multiple institutions would allow more robust data as to the effect of 
Table 1 Changes in Percentages of Women Receiving Awards in our Department of Medicine (DOM) and Biological Sciences Division (BSD) after a Pilot Intervention to Increase Nominations of Female Faculty

\begin{tabular}{|c|c|c|c|c|c|}
\hline & $\begin{array}{l}\text { Post-intervention, mean (range } \\
\text { of percent in each year) }\end{array}$ & $\begin{array}{l}\text { Extended pre-intervention, mean } \\
\text { (range of percent in each year) }\end{array}$ & $\begin{array}{l}p \\
\text { value }\end{array}$ & $\begin{array}{l}\text { Match pre-intervention, mean } \\
\text { (range of percent in each year) }\end{array}$ & $\begin{array}{l}p \\
\text { value }\end{array}$ \\
\hline \multirow[t]{2}{*}{ DOM } & $2018-2019$ & 2006-2017 & & 2016-2017 & \\
\hline & $\begin{array}{l}56 \%(48-65 \%), 23 / 41 \\
2017-2019\end{array}$ & $\begin{array}{l}36 \%(25-50), 79 / 217 \\
2011-2016\end{array}$ & 0.02 & $35 \%(33-37 \%), 14 / 40$ & 0.06 \\
\hline BSD & $59 \%(55-65 \%), 33 / 56$ & $27 \%(18-57 \%), 28 / 102$ & 0.0001 & $\begin{array}{l}2013-2016 \\
34 \%(18-43 \%), 13 / 38\end{array}$ & 0.02 \\
\hline
\end{tabular}

"Extended" pre-intervention represents data from all years of the awards; the "Match" pre-intervention represents the 3 or 2 years of pre-intervention data matched to the 32 years of post-intervention data representing the sensitivity analysis

Table 2 Proportion of Female Awardees by Award Type

\begin{tabular}{|c|c|c|c|c|c|c|}
\hline Award & $\begin{array}{l}\text { DOM-post (2018- } \\
\text { 2019) }\end{array}$ & $\begin{array}{l}\text { DOM-extended pre } \\
(2006-2017)\end{array}$ & $\begin{array}{l}\text { DOM-matched pre } \\
(2016-2017)\end{array}$ & BSD-post & $\begin{array}{l}\text { BSD-extended } \\
\text { pre }\end{array}$ & $\begin{array}{l}\text { BSD-matched } \\
\text { pre }\end{array}$ \\
\hline Educational & $42 \%(8 / 19)$ & $33 \%(37 / 111)$ & $39 \%(7 / 18)$ & \multirow{4}{*}{$\begin{array}{l}57 \% \\
(8 / 14) \\
58 \%(11 / \\
19) \\
42 \% \\
(5 / 12) \\
75 \% \\
(9 / 12)\end{array}$} & $35 \%(7 / 20)$ & $44 \%(4 / 9)$ \\
\hline Clinical* & $67 \%(10 / 15)$ & $37 \%(28 / 76)$ & $19 \%(3 / 16)$ & & $37 \%(10 / 27)$ & $36 \%(5 / 14)$ \\
\hline Research & $60 \%(3 / 5)$ & $48 \%(12 / 25)$ & $75 \%(3 / 4)$ & & $20 \%(3 / 15)$ & $0 \%(0 / 8)$ \\
\hline Other $^{\wedge}$ & $100 \%(2 / 2)$ & $63 \%(5 / 8)$ & $50 \%(1 / 2)$ & & $73 \%(8 / 11)$ & $67 \%(4 / 6)$ \\
\hline
\end{tabular}

*Many of the DOM clinical awards were not nomination based (primarily based on productivity) while all of the BSD awards were nomination based ${ }^{\wedge}$ Other awards included diversity, community engagement, and leadership awards

the intervention. Finally, our initiative focused on women nominating women. Ideally, equitable nominations would not rely only on women nominating women (i.e., DOM-WC). Furthermore, this initiative could expand beyond increasing female nominations to including other underrepresented populations. Therefore, the next steps include formalizing widespread support for institutional leadership to be more thoughtful in their approach to equitable nominations for awards. In sum, nomination bias is likely pervasive and other programs, sections, departments, and/or divisions could easily develop low-resource, feasible nominating processes at their institutions.

Valerie G. Press, $M D, M P H^{1}$

Megan Huisingh-Scheetz, $M D^{2}$

Julie Oyler, $M D^{2}$

${ }^{1}$ Departments of Medicine and Pediatrics, University of Chicago,

Chicago, IL, USA

${ }^{2}$ Department of Medicine, University of Chicago, Chicago, USA

Corresponding Author: Valerie G. Press, MD, MPH; Departments of Medicine and Pediatrics, University of Chicago, Chicago, IL, USA (e-mail: vpress@medicine.bsd.uchicago.edu).

Funding VG Press has research support from the National Heart Lung and Blood Association (RO3HL144883 and RO1HL146644) and the American Lung Association. M Huisingh-Scheetz has received research support from the National Institute on Aging (K23AG049106).

\section{Compliance with Ethical Standards:}

Conflict of Interest: VG Press also discloses consultant fees from Roundglass LLC, Vizient Inc, and Humana. M Huisingh-Scheetz has received research support from the National Institute on Aging (K23AG049106). The authors have no other relevant affiliations or financial involvement with any organization or entity with a financial interest in or financial conflict with the subject matter or materials discussed in the manuscript apart from those disclosed.

\section{REFERENCES}

1. Silver JK, Bank AM, Slocum CS, et al. Women physicians underrepresented in American Academy of Neurology recognition awards. Neurology. 2018;91(7): e603-e614.

2. Silver JK, Bhatnagar S, Blauwet CA, et al. Female Physicians Are Underrepresented in Recognition Awards from the American Academy of Physical Medicine and Rehabilitation. PMR. 2017;9(10):976-984.

3. Silver JK, Blauwet CA, Bhatnagar S, et al. Women Physicians Are Underrepresented in Recognition Awards from the Association of Academic Physiatristts. Am J Phys Med Rehabil. 2018;97(1):34-40.

4. Silver JK. Why are women excluded from medical society awards? STAT. 2017. Available at: https://www.statnews.com/2017/07/19/women-excluded-medical-society-awards/. Accessed May 1, 2020.

5. Abbuhl S, Bristol MN, Ashfaq H, et al. Examining Faculty Awards for Gender Equity and Evolving Values. J Gen Intern Med. 2009;25(1):57-60.

6. Heath JK, Weissman GE, Clancy CB, Shou H, Farrar JT, Dine CJ. Assessment of Gender-Based Linguistic Differences in Physician Trainee Evaluations of Medical Faculty Using Automated Text Mining. JAMA Netw Open. 2019;2(5):e193520.

Publisher's Note: Springer Nature remains neutral with regard to jurisdictional claims in published maps and institutional affiliations. 